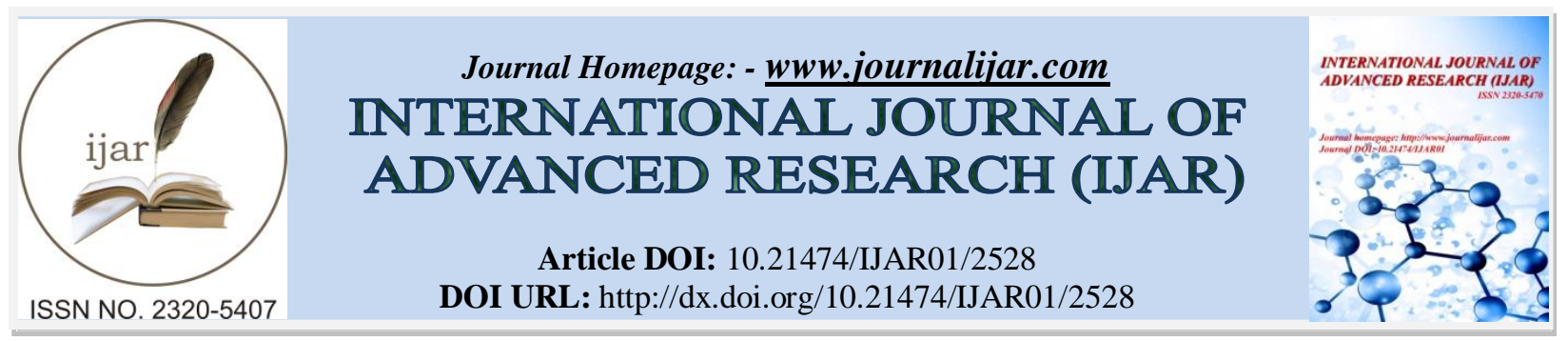

RESEARCH ARTICLE

\title{
SOCIAL WORK AND INCLUSIVE EDUCATION FOR CHILDREN WITH SPECIAL NEEDS.
}

Anusuya K. Yadav.

Assistant Professor, Amity Institute of Rehabilitation Sciences, Amity University, Uttar Pradesh.

\section{Manuscript Info}

Manuscript History

Received: 25 October 2016

Final Accepted: 23 November 2016

Published: December 2016

Key words:-

Social Work , Inclusion, Inclusive

Education, Children with Special

Needs.

\section{Abstract}

Inclusive education can be understood within a number of varied frameworks, namely, the cultural, historical, political and social paradigm keeping in mind that Inclusion is an elaborate interaction that is taking place within social structures and policy enactment. The thematic paper emanates from the social worker's intervention as facilitator for learners with disabilities in inclusive education with its aim to explore and explain the role of the social worker as facilitator in inclusive education. Throughout the discussion we can interpret and conclude that the social worker does not need new skills to be able to facilitate learners with disabilities in inclusive education in order to deal with children with special needs. The social worker can draw on already existing skills ,increasing participation and promoting advocacy human rights, cultures and communities, and reducing exclusion within and from the social sphere.

Copy Right, IJAR, 2016,. All rights reserved.

\section{Moving Forward - Inclusive Education:-}

"Inclusion" has become a catchphrase, not only among the educationists, but also among administrators, policy makers/implementers, human rights advocates (particularly those who advocate for the rights of people with disabilities) and social workers (who advocate for social justice and empowerment of vulnerable members of society). Inequality in the access of social services and participation in social activities are arguably some of the greatest challenges that the world has been experiencing for some time. People have been excluded based on their abilities. Despite the complexity of inclusive education, many countries have seen the importance of educating children together, regardless of their abilities. The inclusive education philosophy recognizes and appreciates that all humans have a right to social services regardless of their orientation. It accepts individuals as unique, recognizing that all have a right to develop their abilities/capabilities (Cameron \& Valentine, 2001). It focuses on the need to foster people's participation and eliminating all forms of discrimination in society. The philosophy of inclusion is thus important in ensuring that people develop social skills needed for their daily living (Noyoo, 2000).

There is extensive discussion of the term "special educational needs" in the literature on special education, and many definitions have been proposed both in Ireland and internationally. These definitions have developed for a number of different purposes, for example (a) educational planning and provision at the system level, (b) the differentiation of individuals for research purposes, and (c) the identification of the special educational needs of an individual to enable educational intervention to be established.

Educational Needs Act (2004) defines the term "special educational needs" as a restriction in the capacity of the person to participate in and benefit from education on account of an enduring physical, sensory, mental health or 
learning disability or any other condition which results in a person learning differently from a person without that condition .(Government of Ireland, 2004b, section 1).

Inclusive education means that all students attend and are welcomed by their neighborhood schools in ageappropriate, regular classes and are supported to learn, contribute and participate in all aspects of the life of the school. Inclusive education is about how we develop and design our schools, classrooms, programs and activities so that all students learn and participate together. Neighbourhood schools are the heart of our communities, and Inclusion BC believes they are essential for a quality inclusive education system.

\section{Benefits of Inclusive Education:-}

All children benefit from inclusive education. It allows them to:

Develop individual strengths and gifts, with high and appropriate expectations for each child.

Work on individual goals while participating in the life of the classroom with other students their own age.

1. Involve their parents in their education and in the activities of their local schools.

- Foster a school culture of respect and belonging. Inclusive education provides opportunities to learn about and accept individual differences, lessening the impact of harassment and bullying.

1. Develop friendships with a wide variety of other children, each with their own individual needs and abilities.

4 Positively affect both their school and community to appreciate diversity and inclusion on a broader level.

Inclusive education brings all students together in one classroom and community, regardless of their strengths or weaknesses in any area, and seeks to maximise the potential of all students. Inclusion is an effort to make sure that diverse learners - those with disabilities, different languages and cultures, different homes and family lives, different interests and ways of learning - are exposed to teaching strategies that reach them as individual learnersInclusive schools ask teachers to provide appropriate individualized supports and services to all students without the stigmatization that comes with separation Teachers in inclusive classrooms vary their styles to enhance learning for all students. The purpose of education is to ensure that all students gain access to knowledge, skills, and information that will prepare them to contribute as a social responsibility towards communities and workplaces. The central purpose becomes more challenging as we strive to meet these challenges, the involvement and cooperation of educators, parents, and community leaders is vital for the creation of better and more inclusive schools.

\section{Seven Principles for Inclusive Education:- Teaching All Students:-}

Educators should take several different approaches to teaching the same material so that information becomes more interesting and tangible to a greater number of students.

\section{Exploring Multiple Identities:-}

Students who are proud of themselves and excited by the world around them will be more compassionate and understanding people; the same is true for educators.

\section{Preventing Prejudice:-}

Educators should take a proactive approach to debunking preconceived stereotypes and preventing them from escalating into prejudices and negative biases.

\section{Promoting Social Justice:-}

Students are good judges of what is fair, especially when they are affirmatively challenged to consider issues of social justice. Educators should talk to them about issues of social justice and injustice in terms of fair versus unfair, respectful versus disrespectful.

\section{Choosing Appropriate Materials:-}

Inclusive classrooms use books and materials that reflect accurate images of diverse peoples and challenge stereotypes.

Teaching and Learning About Cultures and Religions:-

Educators should create curiosity and expand students' horizons by teaching about others in a positive manner. Students should have the opportunity to learn from their peers as well as other cultures. 


\section{Adapting and Integrating Lessons Appropriately:-}

Educators should be flexible when using and adapting lessons in our curricula, as well as in prescribed curricula in general. Many of the most teachable moments are unplanned and unscripted.

\section{Disability - Advocacy of Human Rights:-}

Priestly (2003) asserts that within the framework of the rights and resources, issues of social inclusion of people with disabilities in the community (social) activities have taken a centre stage at global level. He makes reference to Article 28 of the United Nations Convention on the Rights of a Child (UNCRC) that articulates the need for the holistic wellbeing of a child. Other international instruments include; the Convention on Rights of People with Disabilities (CRPD)- this is aimed at protecting, promoting and ensuring that people with disabilities enjoy all the basic rights irrespective of their abilities.

The Salamanca Statement on Principles, Policy and Practices in Special Needs Education emphasis on the need to educate all children together regardless of their circumstances. The Standard Rules on the Equalization of Opportunities for Persons with Disabilities on the other hand aims at ensuring that all barriers to effective participation of persons with disabilities in social activities are removed (UN, 1993; Guernsey, Nicoli \& Ninio, 2007; Barron \& Amerena, 2007; Clement \& Read, 2008; Croft, 2010).

\section{Social Worker - A Facilitator in Inclusive Education:-}

In order to develop a better understanding of the role of social worker, rendering services to learners with disabilities in inclusive setting, the primary concern of the social worker is to identify unmet needs of people by using their extensive knowledge about human development, human diversity, social systems, eco-systems and strengths. The primary concern caters to the improvement of social functioning of people in interaction with their environment.

Based on the above discussion, the impactful role of the social worker as a facilitator in inclusive education are -

- To protect and care for vulnerable individuals and groups in society by improving human well being and alleviating operation and other forms of social injustice in reference to persons and children with special needs.

1. Empower and advocate rights and policies which have been dispensed as the human rights of persons with disabilities, promote social and economic justice leading to upliftment of the disabled, combat social isolation.

$\square$ To create sensitisation and awareness, removing barriers to participate in the society, making sure that the children with special needs have the same chance to be a part of the society and contribute to it at their own particular level of ability.

- Provide equal access to children with special needs/persons with disabilities equal access to physical environment, learning environment, appropriate health and social care provision, and training and employment opportunities.

1. Assist with contacting families of children with special educational needs in the area of the school; Participate in the identification of special needs of the pupils in school;Orientate and provide information to parents and pupils when they enter school;

1. Provide information on rights and opportunities for social and legal protection for pupils with special educational needs; Identify traces from violence on pupils and inform the authorities for child protection;

- Carry out individual and group meetings with all pupils at the school on various issues; Consult school management to adapt the school environment in a welcoming environment for pupils with disabilities.

1. Organize information campaigns and training of pupils, parents and teachers; Contact with different institutions for social and educational services in the community, Provide school mediation in conflict relationships.

\section{Where to Get Help:-}

If a child has a disability, social workers and other professionals can help the child and family. Role of social workers in a variety of settings such as:

- hospitals and long-term care facilities

a. schools

1. child welfare agencies

- mental health centres

- private practice 


\section{Social Workers in Hospitals and Long-Term Care Facilities:-}

Doctors diagnose some disabilities at birth or even before birth while others are discovered later. Illness or injury may cause other disabilities It is normal to feel all sorts of emotions when a child is diagnosed with a disability.

\section{Hospital social workers can help you:-}

- think about how you feel about the disability

- figure out what you and your family member need

- help you find resources in the community that may help you

- help you with applications for services

- connect with other families of children with the same disabilities

- connect with support groups

\section{Social Workers in Schools:-}

Children and teenagers with disabilities often receive services in the public school system. Depending on the disability, your child could begin getting services when he or she is a baby or preschooler. Or, your child may start getting services later when you and your child's teachers realize that he or she needs them. The roles of school social workers vary from one school district to another and from one state to the next. School social workers may work with children in general education, special education, or both. School social workers may talk with children and their parents when a child is considered for special education services. Social workers are often part of the team involved in the evaluation when a child has behavior or mental health concerns. School social workers may provide counseling to individual children, work with children in groups, or work with entire classrooms. School social workers may help families get services that they need or connect families to other community agencies. School social workers may consult with teachers, parents, and other adults in the children's lives. School social workers may address needs at the individual level, group level, and school level. When working with individual children or groups, school social workers may work with children on issues from behaviour problems, hygiene, or coping skills to substance abuse issues and grief.

\section{Early intervention and preschool services may include:-}

- speech therapy

- occupational or physical therapy

- social work or psychological services

- assistive technology

- audiology or vision services

- others services not listed here

Special education services for Kindergarten through 12th grade may include:-

- education in the general classroom and/or in a resource room

- school social work services

- speech and language services

- occupational therapy

- adaptive physical education

- transportation

The services provided depend on your child's unique needs depending on individual needs. The roles of school social workers vary from one school district to another. School social workers may work with children in general education, special education, or both. School social workers may talk with children and their parents when a child is being considered for special education services. It depends on the type of disability. Social workers are often part of the team of people involved in the evaluation when a child has behavior challenges or mental health concerns.

School social workers may provide counseling to individual children, work with children in groups, or work with entire classrooms. School social workers may help families get services that they need or connect families to other community agencies. School social workers may consult with teachers, parents, and other adults in the children's lives. School social workers may address needs at the individual level, group level, and school level. 
When working with individual children or groups, school social workers may work with children on issues such as:

- Behavior problems

- Emotional issues

- Getting along with friends

- Getting along with adults

- Hygiene

- Anger management

- Coping skills

- Grief

- Substance abuse

The family and the school are the central places for the development of children. Herein can be found the hopes for the next generation. There are often gaps in this relationship, within the school, within the family, and in their relationships to each other and to the needs of students. There are gaps between aspirations and realities, between manifest need and available programs. In the dynamic multicultural world of the child today, there are gaps between particular cultures and what education may offer. Everywhere it is a top public priority that children develop well and that schools support that development. Nevertheless, aspirations are unfulfilled, policies fail, and otherwise effective programs fail with certain students. School social workers practice in the space where children, families, schools, and communities encounter one another, where hopes can fail, where gaps exist, and where education can break down. Throughout the world, schools are becoming the main public institution for social development. Schools are working to include those previously excluded from the opportunity of education. They are raising standards for educational outcomes to prepare citizens to participate in a multinational world, bound together by communication and by economic and social relations. The school social worker is becoming a useful professional to assist children who are marginalized - whether economically, socially, politically, or personally - to participate in this. Social workers work to make the education process effective. To do this, their central focus is working in partnership with parents on the pupil in transaction with a complex school and home environment. Education has become crucial, not only for each person to cope with the demands of modern living, but also for national economic survival (Friedman, 2005). It is very serious work. As a consequence of education's enhanced mission, an outcomebased education system is developing.

\section{Conclusion:-}

Social Work is anchored on promoting positive change in individuals and society at large, so education for students with disabilities is pivotal in providing them with equality of opportunity, improving their living standards, and contributing to the development of the country (Pincus and Minahan 1973 cited by Noyoo, 2000). Education is also important in that it augments the problem- solving and coping capacities of people, and social work is all about improving people's problem solving abilities so that they can lead a decent lifestyle devoid of social problems. Hence, an all inclusive education system is important in social work (Noyoo, 2000). Further, Oliver (1996) states that welfare provisions such as education play a vital role in the integration of people in society. Hence, education is important in social work.

Further, it is important for Social Workers to have an in-depth knowledge and understanding of disability because theories of disability do influence their practice and future research in the sense that social workers ought to effective positive functioning among the marginalized people in society through evidence based knowledge (Cunningham \& Fleming, 2009).

\section{References:-}

1. Armstrong, F., Armstrong, D. \& Barton, L. (eds). (2000). Inclusive Education. Policy, Context and Comparative Perspectives. London. David Fulton Publishers.

2. Bigby, C. \& Frawley, P. (2010). Social Work practice and intellectual disability. New York: Palgrave Macmillan.

3. Cambra, C. \& Silvestre, N. (2003). Students with special educational needs in the inclusive classroom: Social integration and self-concept. European Journal of Special Needs Education, 18, 197-208.

4. Clark, L. R. (2008). Inclusive Education in Secondary Schools: Perspectives of Students with Disabilities. New York: State University.

5. National Association of Social Workers (2002).NASW Standarts for school social work practice. 